\title{
Papers
}

\section{Conservative management of persistent postnatal urinary and faecal incontinence: randomised controlled trial}

\author{
Topic: $66 ; 68 ; 159 ; 161$ \\ Cathryn M A Glazener, G Peter Herbison, P Don Wilson, Christine MacArthur, Gordon D Lang, \\ Harry Gee, Adrian M Grant
}

\begin{abstract}
Objectives To assess the effect of nurse assessment with reinforcement of pelvic floor muscle training exercises and bladder training compared with standard management among women with persistent incontinence three months postnatally.

Design Randomised controlled trial with nine months' follow up.

Setting Community intervention in three centres (Dunedin, New Zealand; Birmingham; Aberdeen). Participants 747 women with urinary incontinence three months postnatally, allocated at random to intervention (371) or control (376) groups.

Intervention Assessment by nurses of urinary incontinence with conservative advice on pelvic floor exercises at five, seven, and nine months after delivery supplemented with bladder training if appropriate at seven and nine months.
\end{abstract}

Main outcome measures Primary: persistence and severity of urinary incontinence 12 months after delivery. Secondary: performance of pelvic floor exercises, change in coexisting faecal incontinence, wellbeing, anxiety, and depression.

Results Women in the intervention group had significantly less urinary incontinence: $167 / 279$ (59.9\%) v 169/245 (69.0\%), difference 9.1\% (95\% confidence interval $1.0 \%$ to $17.3 \%, \mathrm{P}=0.037$ ) for any incontinence and 55/279 (19.7\%) v 78/245 (31.8\%), difference $12.1 \%$ ( $4.7 \%$ to $19.6 \%, \mathrm{P}=0.002)$ for severe incontinence. Faecal incontinence was also less common: 12/273 (4.4\%) v 25/237 (10.5\%), difference $6.1 \%(1.6 \%$ to $10.8 \%, \mathrm{P}=0.012)$. At 12 months women in the intervention group were more likely to be performing pelvic floor exercises $(218 / 278(79 \%) v$ 118/244 (48\%), $\mathrm{P}<0.001)$.

Conclusions A third of women may have some urinary incontinence three months after childbirth. Conservative management provided by nurses seems to reduce the likelihood of urinary and coexisting faecal incontinence persisting 12 months postpartum. Further trials for faecal incontinence are needed.

\section{Introduction}

Incontinence is a common and distressing problem after childbirth. Three months after delivery $20-30 \%$ of women have urinary incontinence ${ }^{1-3}$ and about $4 \%$ have faecal incontinence. ${ }^{45}$ Despite the extent of the problem, there is little evidence on which to base best management.

Conservative treatments, centring on retraining the pelvic floor musculature, have been shown to be effective among older women with stress incontinence. ${ }^{67}$ However, in one of the few trials that included postpartum women, Sleep and Grant found no reduction three months after delivery for women in whom the use of postnatal pelvic floor exercises was reinforced compared with standard management given to all women who have recently given birth. ${ }^{8}$ This finding, together with electrophysiological evidence of spontaneous nerve recovery during this period, ${ }^{9}$ suggested that targeting women with persistent incontinence would be more effective. ${ }^{10}$

We developed an assessment and management intervention with nurses, based on the model successfully tested by O'Brien and colleagues in a mixed community based population of older women. ${ }^{11}$ We tested its use in a pilot study. ${ }^{10}$ We then carried out a randomised controlled trial to examine the effect on incontinence at 12 months in women who had urinary incontinence three months after childbirth.

\section{Methods}

Approval was obtained from the research ethics committees in each of the three centres. Women living within a $50 \mathrm{~km}$ (30 mile) radius and who delivered in these units during a 12 month recruitment period were contacted by post three months after delivery (October 1993 to September 1994). They were asked to complete a questionnaire about urinary and faecal incontinence, associated symptoms, and other health issues. We did not approach women whose babies were stillborn or died as neonates. We used a slightly modified version of the questionnaire tested in the preceding pilot study. ${ }^{10}$

We invited women who had urinary incontinence in the preceding month (defined as any involuntary

\author{
Health Services \\ Research Unit, \\ University of \\ Aberdeen, Polwarth \\ Building, \\ Foresterhill, \\ Aberdeen, \\ AB25 2ZD \\ Cathryn M A \\ Glazener \\ senior clinical \\ research fellow \\ Adrian M Grant \\ director \\ Department of \\ Preventive and \\ Social Medicine, \\ Dunedin School of \\ Medicine, \\ University of Otago, \\ PO Box 913, \\ Dunedin, New \\ Zealand \\ G Peter Herbison \\ statistician \\ Department of \\ Women's and \\ Children's Health, \\ Dunedin School of \\ Medicine, \\ University of Otago \\ P Don Wilson \\ urogynaecologist \\ Department of \\ Public Health and \\ Epidemiology, \\ University of \\ Birmingham, \\ Birmingham \\ B15 2TT \\ Christine \\ MacArthur \\ professor of maternal \\ and child \\ epidemiology \\ Department of \\ Obstetrics and \\ Gynaecology, \\ Aberdeen Royal \\ Hospitals Trust, \\ Aberdeen \\ AB25 2ZL \\ Gordon D Lang \\ obstetrician \\ continued over
}

BMJ 2001;323:1-5 
Department of Fetal Medicine,

University of

Birmingham,

Birmingham

B15 2TG

Harry Gee

obstetrician

Correspondence to:

C M A Glazener

c.glazener@

abdn.ac.uk loss of urine) to participate in the trial. After signed consent, they were randomly allocated to receive the nurse assessment and treatment programme or to a control group. Women were followed up by repeat questionnaire at 12 months after delivery, equivalent to around seven months after the first visit of the nurse to the intervention group.

\section{Intervention}

The nurses (a midwife, a health visitor, and a continence advisor) received a short course of specialised training in conservative management from local physiotherapists. The intervention comprised a structured home interview designed to identify different types of incontinence at five months after delivery. The nurse identified women whose symptoms were not typical of stress or urge incontinence or who had evidence of urinary tract infection; these women were referred to their primary care physician but remained enrolled in the trial for follow up and analysis.

The nurse used a standard set of diagrams and instructions to teach the women in the intervention group about the anatomy of the pelvic floor and muscle contraction regimens. ${ }^{12}{ }^{13}$ After preparatory exercises to identify the pelvic floor musculature, the women were asked to follow a basic exercise programme of eight to ten sessions each day of fast and slow contractions with the aim of 80-100 contractions daily. The nurse visited again and reinforced the instructions at seven and nine months after delivery. Women with symptoms of frequency or urgency also received instruction on bladder training at these later sessions. This aimed to increase bladder capacity by deferring voiding for progressively longer periods of time; the women were also advised to avoid drinks that contain caffeine. The control group did not receive any visits from research nurses. Like the intervention group, they had received peripartum preparation, which sometimes included pelvic floor exercises, ${ }^{14}$ and could seek medical advice.

\section{Outcomes}

The primary outcome measure was persistence of any urinary incontinence. Secondary outcomes included "severe" urinary incontinence (defined as at least once a week) and faecal incontinence (see box). Women who reported faecal incontinence "sometimes," "often," or "always" were classified as having severe incontinence. Other variables measured were the use and frequency of pelvic floor exercises, use of pads, an overall rating of severity of urinary incontinence with a visual analogue scale, a measure of general wellbeing (see box), and anxiety and depression measured by the hospital anxiety and depression scale. ${ }^{15}$

\section{Power calculation}

We aimed to recruit 660 women, giving $80 \%$ power to detect a $10 \%$ difference in persistence of urinary incontinence between the two groups, assuming that $75 \%$ of the control group would still be incontinent at one year after delivery. These figures were conservatively based on findings in the pilot study. ${ }^{10}$

\section{Randomisation}

Randomisation was achieved with remote access to a computer program in Dunedin. It registered each woman before presenting the allocation by using stratification by parity (four versus fewer), method of

\section{Phrasing of questions}

Urinary incontinence

At present, do you ever lose any urine when you don't mean to? (yes/no)

In the past month, how often has this happened on average? (less than twice a month/twice a month/once a week/a few times a week/once a day/twice a day/three or more times a day) (severe $=$ once a week or more often)

\section{Faecal incontinence}

Do you ever lose control of wind or bowel motions from your back passage between visits to the toilet? (no/rarely/sometimes/often/always) $($ severe $=$ sometimes or more often $)$

\section{General wellbeing}

How are you feeling generally? (very well/well/not very well/not at all well)

Type of urinary incontinence Do you lose urine when you: (yes/no)

Stress: cough, laugh, sneeze, run, jump, or play sport (if not also urge or mixed)

Urge: feel an urgent desire to pass water and are unable to reach the toilet in time (if not also stress or mixed)

Mixed: At some other time (including women who ticked both stress and urge)

delivery (caesarean versus other), and frequency of incontinence (at least once a week versus less). The intervention could not be performed blind, but the collection of outcome data was by anonymised questionnaire, which was identified only by a study number and which could not be related back to trial allocation at the time of data entry.

\section{Analysis}

Groups were compared with $\chi^{2}$ test or $t$ tests as appropriate, with results expressed as absolute or relative differences with $95 \%$ confidence intervals. Analysis was by intention to treat. Prespecified secondary analyses were stratified by initial severity of incontinence (at least once a week versus less) and by type of incontinence (stress, urge, or mixed, see box). We explored the impact of differential loss to follow up with analyses stratified by centre.

\section{Results}

Of 10985 questionnaires sent to women three months postnatally, $7879(72 \%)$ were returned. Among the respondents, 2632 (33\%) had urinary incontinence in the previous month, and 747 (28\%) of these consented to participate in the trial (figure 1). The trial groups were comparable at baseline (table 1). However, the women who had incontinence but who did not participate were younger, had fewer spontaneous vaginal deliveries, more intact perineums, lighter babies, and were less likely to have severe incontinence (table 1).

In the intervention group, $316 / 371$ received the intervention as allocated, but all women were included in the intention to treat comparison with the 376 in the control group. At follow up, women in the intervention group were more likely to report performing some pelvic floor exercises in the previous month $(218 / 278$ $(79 \%) v 118 / 244$ (48\%), 95\% confidence interval for 


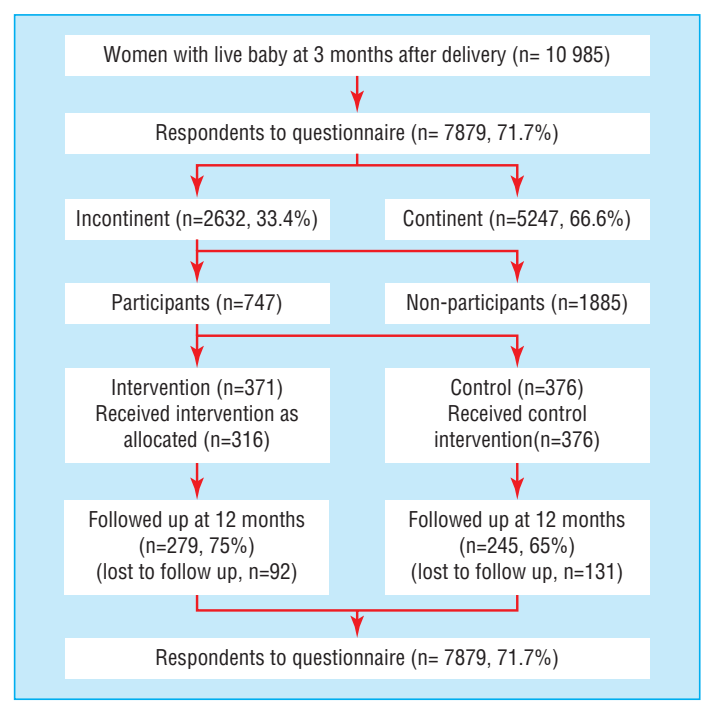

Fig 1 Population studied. Reasons for not receiving active intervention as allocated include new pregnancy, too busy, moved away, family problems, incontinence resolved, non-stress or urge incontinence

difference $22 \%$ to $38 \%, \quad \mathrm{P}<0.001)$ and to be performing more contractions (mean (SD) number per day 20 (29) v 5 (15), 11 to $19, \mathrm{P}<0.001)$. These women were also significantly less likely to have any incontinence, which was reflected in a difference in severe incontinence (table 2). Overall ratings of severity, use of pads, and number of pad changes were lower in the intervention group, which also reported less faecal incontinence to motions and less severe faecal incontinence (table 2). Although there were no significant differences in general wellbeing or depression, women in the intervention group were less anxious than those in the control group (table 2).

The results of the stratified analyses were consistent with the overall results in favouring the intervention group. The absence of significant heterogeneity suggested that the intervention was effective irrespective of type or severity of incontinence (figs 2 and 3).

More women in the intervention group returned a completed follow up questionnaire $(75 \% v 65 \%)$. Table 3 shows that the women who did not respond at follow up were more likely to have had severe incontinence at baseline $(65 \% v 52 \%)$, though this was not affected by
Table 1 Baseline characteristics of intervention, control, and non-participant groups. Figures are number (percentage) of women unless stated otherwise. Not all data were available for all women

\begin{tabular}{|c|c|c|c|}
\hline & $\begin{array}{c}\text { Intervention } \\
\quad(n=371)\end{array}$ & $\begin{array}{l}\text { Control } \\
(\mathrm{n}=376)\end{array}$ & $\begin{array}{c}\text { Non-participants } \\
(\mathrm{n}=\mathbf{1 8 8 5})\end{array}$ \\
\hline \multicolumn{4}{|l|}{ Centre: } \\
\hline Dunedin & 54 & 60 & 247 \\
\hline Birmingham & 145 & 142 & 1023 \\
\hline Aberdeen & 172 & 174 & 615 \\
\hline Mean (SD) age (years) & $29.6(5.2)$ & $29.4(5.1)$ & $28.4(5.4)$ \\
\hline Primiparous & $134(36.7)$ & $139(37.6)$ & $735(39.4)$ \\
\hline \multicolumn{4}{|l|}{ Incontinence before index pregnancy: } \\
\hline Primiparas & $14(10.4)$ & $10(7.2)$ & $81(11.0)$ \\
\hline Multiparas & $121(52.4)$ & $112(48.5)$ & $455(40.3)$ \\
\hline \multicolumn{4}{|l|}{ Method of delivery: } \\
\hline Spontaneous vaginal & $285(78.3)$ & $291(78.6)$ & $1347(72.3)$ \\
\hline Assisted vaginal* & $50(13.7)$ & $51(13.8)$ & $291(15.6)$ \\
\hline Caesarean section† & $29(8.0)$ & $28(7.6)$ & $226(12.1)$ \\
\hline \multicolumn{4}{|l|}{ Perineum: } \\
\hline Intact & $124(34.4)$ & $128(35.9)$ & $754(42.1)$ \\
\hline Tear & $154(42.8)$ & $160(44.8)$ & $640(35.8)$ \\
\hline Episiotomy (with or without tear) & $82(22.8)$ & $69(19.3)$ & $395(22.1)$ \\
\hline Mean (SD) birthweight $(\mathrm{g})$ & $3478(505)$ & $3416(523)$ & $3389(584)$ \\
\hline Severe incontinence (at least once a week) & $212(57.1)$ & $204(54.3)$ & $882(46.8)$ \\
\hline \multicolumn{4}{|l|}{ Type of incontinence: } \\
\hline Stress only & $199(54.1)$ & $187(51.3)$ & $1003(54.6)$ \\
\hline Urge only & $53(14.4)$ & $61(16.8)$ & $308(16.8)$ \\
\hline Mixed & $116(31.5)$ & $116(31.9)$ & $526(28.6)$ \\
\hline Faecal incontinence (motions) & $57(16.3)$ & $54(15.1)$ & $259(14.8)$ \\
\hline Mean (SD) anxiety scoreł & $6.9(3.78)$ & $7.0(3.76)$ & $7.25(3.76)$ \\
\hline Mean (SD) depression scoreł & $6.18(3.89)$ & $5.84(3.66)$ & $6.69(3.97)$ \\
\hline
\end{tabular}

${ }^{*}$ Breech, vacuum/ventouse, forceps.

†Of these 12,13 , and 103, respectively, were elective.

‡Derived from hospital anxiety and depression scale. ${ }^{14}$

trial allocation among non-responders $(69 \% v 63 \%)$. The differential loss to follow up was confined to participants in one centre (Birmingham). Stratified analyses restricted to the two other centres, which did not have such losses, suggested larger rather than smaller effects $(51 \%$ still incontinent in the intervention group $v 67 \%$ in the controls, $\mathrm{P}=0.004)$.

\section{Discussion}

Nurse assessment and conservative treatment targeted at women with incontinence three months postnatally moderately reduces the risk of incontinence a year later. The difference in the primary outcome measure,

Table 2 Incontinence and other outcome measures at 12 months. Figures are numbers (percentage) of women and means (95\% confidence interval)

\begin{tabular}{|c|c|c|c|c|}
\hline & Intervention (279) & Control (245) & $\begin{array}{l}\text { Absolute difference } \\
\text { (95\% CI for difference) }\end{array}$ & Significance \\
\hline Urinary incontinence (any) & $167(59.9)$ & $169(69.0)$ & $9.1(1.0$ to 17.3$)$ & $\chi^{2}=4.33, P=0.037$ \\
\hline Urinary incontinence $\left(\right.$ severe $\left.^{\star}\right)$ & 55 (19.7) & $78(31.8)$ & $12.1(4.7$ to 19.6$)$ & $\chi^{2}=9.49, P=0.002$ \\
\hline Mean overall rating of severity $(\mathrm{n}=142$ and 142) & $2.8(2.4$ to 3.1$)$ & $3.6(3.1$ to 4.0$)$ & $0.8(0.22$ to 1.36$)$ & $t=-2.73, P=0.007$ \\
\hline Any pad use & $41 / 276(14.9)$ & $55 / 245(22.4)$ & $7.5(0.9$ to 14.3$)$ & $\chi^{2}=4.49, P=0.034$ \\
\hline Mean No of pad changes $\neq(n=275$ and 244) & $0.19(0.13$ to 0.25$)$ & $0.34(0.25$ to 0.43$)$ & $0.15(0.04$ to 0.26$)$ & $t=-2.65, P=0.008$ \\
\hline Any faecal incontinence (to motions) & $12 / 273(4.4)$ & $25 / 237(10.5)$ & $6.1(1.6$ to 10.8$)$ & $\chi^{2}=6.25, P=0.012$ \\
\hline Severe faecal incontinence (to motions§) & $5 / 273(1.8)$ & $12 / 237(5.1)$ & $3.3(0.02$ to 6.4$)$ & $\chi^{2}=3.17, P=0.075$ \\
\hline General feeling of wellbeing (very well) & $130 / 276(47.1)$ & $110 / 244(45.1)$ & $2.0(-6.5$ to 10.6$)$ & $\chi^{2}=0.139, P=0.709$ \\
\hline Mean HAD anxiety scoref ( $n=238$ and 219) & $6.1(5.6$ to 6.5$)$ & $6.8(6.3$ to 7.3$)$ & 0.7 (0.05 to 1.43$)$ & $t=-2.08, P=0.038$ \\
\hline Mean HAD depression scoref ( $\mathrm{n}=238$ and 219$)$ & 4.8 (4.4 to 5.3$)$ & $5.2(4.7$ to 5.7$)$ & $0.4(-0.28$ to 1.02$)$ & $t=-1.13, P=0.260$ \\
\hline
\end{tabular}

* Severe urinary incontinence defined as at least once a week.

†Analogue scale range: $0=$ no problem at all to $10=$ can't think of anything worse.

łlncontinent women only.

$\S$ Severe faecal incontinence defined as sometimes, often, or always.

IHospital anxiety and depression score range: 0 (no anxiety or depression) to 21 (maximum score). 


\begin{tabular}{|c|c|c|c|c|c|}
\hline & Treatment & Control & \multicolumn{2}{|c|}{ Relative risk ( $95 \%$ Cl fixed) } & $\begin{array}{l}\text { Relative risk } \\
(95 \% \text { Cl fixed) }\end{array}$ \\
\hline All women & $167 / 279$ & 169/245 & \multicolumn{2}{|l|}{-} & 0.87 (0.76 to 0.99$)$ \\
\hline Low initial severity ( $<1 /$ week) & $68 / 130$ & $75 / 123$ & \multirow{2}{*}{\multicolumn{2}{|c|}{$\rightarrow$}} & 0.86 (0.69 to 1.07$)$ \\
\hline High initial severity (>1/week) & 99/149 & $94 / 122$ & & & 0.86 (0.74 to 1.00$)$ \\
\hline Stress incontinence initially & $91 / 156$ & $87 / 124$ & \multicolumn{2}{|l|}{$\rightarrow$} & 0.83 (0.70 to 0.99$)$ \\
\hline Urge incontinence initially & $18 / 41$ & $25 / 43$ & \multirow{2}{*}{\multicolumn{2}{|c|}{$\rightarrow$}} & 0.76 (0.49 to 1.16$)$ \\
\hline \multirow[t]{2}{*}{ Mixed incontinence initially } & $57 / 79$ & $54 / 67$ & & & 0.90 (0.75 to 1.07$)$ \\
\hline & & & $\begin{array}{ccc}0.2 & 0.5 & 1 \\
\text { Favours } \\
\text { conservative } \\
\text { treatment }\end{array}$ & $\begin{array}{c}2 \\
\text { Favours } \\
\text { control }\end{array}$ & \\
\hline
\end{tabular}

Fig 2 Relative risk of any incontinence at 12 months postpartum according to initial severity of incontinence and initial type of incontinence with conservative treatment compared with control

\begin{tabular}{|c|c|c|c|c|c|}
\hline \multirow[b]{2}{*}{ All women } & \multirow{2}{*}{$\begin{array}{l}\text { Treatment } \\
55 / 279\end{array}$} & \multirow{2}{*}{$\begin{array}{l}\text { Control } \\
78 / 245\end{array}$} & \multicolumn{2}{|c|}{ Relative risk (95\% Cl fixed) } & \multirow{2}{*}{$\begin{array}{c}\text { Relative risk } \\
(95 \% \text { Cl fixed) } \\
0.62 \text { ( } 0.46 \text { to } 0.84\end{array}$} \\
\hline & & & $\rightarrow$ & & \\
\hline Low initial severity (<1/week) & $12 / 130$ & $13 / 123$ & - & 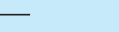 & 0.87 (0.41 to 1.84$)$ \\
\hline High initial severity ( $\geqslant 1 /$ week) & $43 / 149$ & $65 / 122$ & - & & 0.54 (0.40 to 0.73$)$ \\
\hline Stress incontinence initially & $29 / 156$ & $37 / 124$ & $\rightarrow$ & & 0.62 (0.41 to 0.95 ) \\
\hline Urge incontinence initially & $4 / 41$ & $8 / 43$ & $\Rightarrow$ & - & 0.52 (0.17 to 1.61$)$ \\
\hline \multirow[t]{2}{*}{ Mixed incontinence initially } & $21 / 79$ & $31 / 67$ & $\rightarrow$ & & 0.57 (0.37 to 0.90$)$ \\
\hline & & & $\begin{array}{l}0.2 \\
\begin{array}{c}\text { Favours } \\
\text { Fonservative } \\
\text { treatment }\end{array}\end{array}$ & $\begin{array}{c}5 \\
\text { Favours } \\
\text { control }\end{array}$ & \\
\hline
\end{tabular}

Fig 3 Relative risk of severe incontinence (at least once a week) at 12 months postpartum according to initial severity of incontinence and initial type of incontinence with conservative treatment compared with control

any urinary incontinence 12 months after delivery, is unlikely to reflect chance. It suggests that about 11 women would have to be treated to prevent one case of persistent incontinence, with the benefit concentrated among those with severe incontinence. Furthermore, women in the intervention group were significantly less likely to have persistence of faecal incontinence and had lower anxiety scores. There was no evidence of any differential effects among subgroups of women characterised by initial type of urinary incontinence (stress, urge, or mixed). Although the relative risk reduction for "any incontinence" was similar in the analyses stratified by initial severity, the risk of eventually having severe incontinence was principally reduced among women whose initial incontinence was severe. This finding should be interpreted cautiously and as hypothesis generating rather than testing, but it does provide some basis for limiting the intervention to women with more severe incontinence.

Table 3 Differential response rates and incontinence at baseline and outcome at 12 months. Figures are numbers (percentage) of women

\begin{tabular}{|c|c|c|c|}
\hline & \multicolumn{2}{|c|}{ Incontinence } & \multirow[b]{2}{*}{ Significance } \\
\hline & $\begin{array}{l}\text { Up to twice } \\
\text { a month }\end{array}$ & $\begin{array}{l}\text { At least once } \\
\text { a week }\end{array}$ & \\
\hline \multicolumn{4}{|c|}{ According to return of second questionnaire: } \\
\hline Returned $(n=524)$ & $253(48)$ & $271(52)$ & \multirow{2}{*}{$\chi^{2}=10.69, P=0.001$} \\
\hline Not returned $(\mathrm{n}=223)$ & $78(35)$ & $145(65)$ & \\
\hline \multicolumn{4}{|c|}{ In women who did not return second questionnaire: } \\
\hline Intervention $(\mathrm{n}=92)$ & $29(32)$ & $63(69)$ & \multirow{2}{*}{$\chi^{2}=0.584, P=0.444$} \\
\hline Control $(n=131)$ & $49(37)$ & $82(63)$ & \\
\hline
\end{tabular}

\section{Strengths and weaknesses}

Randomisation stratified by parity, method of delivery, and frequency of incontinence ensured that smaller subgroups were evenly distributed between the trial arms. We chose to stratify at para 4 because previous work has shown that the likelihood of urinary incontinence increases considerably after four children (compared with primiparous women). ${ }^{2}$

There was a higher response rate to the 12 month questionnaire in the intervention group, which needs to be taken into account in the interpretation. This would introduce bias if the non-responders in the control group were less likely to be incontinent than those who responded. However, further analysis showed that non-responders had more rather than less severe incontinence initially, suggesting that severity of incontinence was not the factor contributing to their differential response rate. If anything, those lost from the intervention group had more severe incontinence at baseline, and yet it was the women in this group who seemed to benefit most. Furthermore, the difference in response rates was seen in only one of the centres (Birmingham). Secondary analyses restricted to the two other centres indicated a larger rather than smaller effect compared with the overall trial result.

\section{Implications}

The reduction in incontinence contrasts with the findings of a comparable trial, which indicated that providing enhanced instruction on pelvic floor exercises to all postnatal women immediately after delivery was not effective. ${ }^{8}$ However, two thirds of these women would be unlikely to suffer from incontinence in the long term, the active intervention occurred briefly in hospital and was supplemented by diaries and telephone reminders at home for a month, and the intervention was given during the period when spontaneous recovery of nerve damage might be occurring. ${ }^{9}$ Our policy of targeting women who had persistent incontinence was therefore likely to reach a more receptive population at a period when they had more time to devote to their own health.

The intervention resulted in a greater reported use of pelvic floor exercises, consistent with a causal link with the lower rates of incontinence. Another possible mediator is the "social support" provided by repeated contact with the research nurses. In addition to reduced anxiety there was a proportional improvement in general wellbeing and reduction in depression, although these differences did not reach significance. Similar changes in wellbeing and depression among women in the intervention group (albeit without any detectable effect on incontinence) were also seen in the trial of nurse led reinforcement of pelvic floor exercises immediately after delivery.

Our results may be particularly important in guiding the management of persistent faecal incontinence. Recent systematic reviews of all trials of conservative treatment of faecal incontinence found no other trials of pelvic floor exercises versus no treatment and only limited evidence to favour biofeedback and electrical stimulation. $^{16}{ }^{17}$ In our trial the women with faecal incontinence also had urinary incontinence. In the baseline survey there were 329/4814 (7\%) more women continent to urine but incontinent to faeces who were not invited to participate in the trial. Our 


\section{What is already known on this topic}

Vaginal delivery is a risk factor for urinary incontinence

Three months after childbirth $20-30 \%$ of women still experience urinary incontinence

Most women do not seek treatment

\section{What this study adds}

Women will use conservative treatments such as pelvic floor exercises or bladder training

Conservative management prevents persistent urinary incontinence in about one in 10 women who have postnatal incontinence

Coexisting persistent faecal incontinence is also improved

findings regarding faecal incontinence should be interpreted cautiously in view of the scarcity of other information on the management of faecal incontinence and the fact that this was not our primary outcome measure.

Can these results be generalised to an unselected postnatal population? The initial questionnaire to postnatal women had a $72 \%$ response rate, which is high for postal surveys. The demographic characteristics of non-respondents were typical of other non-responders to such surveys, ${ }^{18}$ and their obstetric characteristics suggested that they would be likely to have less incontinence than responders (data not shown). Similarly, the women who were incontinent but did not participate in the study were more "normal" than the trial women in obstetric terms, and they were less likely to have severe incontinence. This might have reduced their motivation to enter the trial.

\section{Conclusion}

Incontinence to urine and faeces commonly dates from pregnancy and childbirth. Conservative management by nurses of postnatal women with persistent incontinence seems to be effective in reducing both urinary and faecal incontinence. The benefit for women with urinary incontinence is greater among those with more severe initial symptoms, which could provide a basis for a more restrictive approach to this form of management. Further randomised trials for faecal incontinence are needed. Further research would also identify the most effective and efficient ways to deliver an intervention of the kind tested in this trial and to assess whether the benefits observed in this study are sustained, particularly among women who have more children by vaginal delivery.

We thank the women who took part and Alison MacDonald, Anne-Marie Rennie, Jane Cook, and Jane Harvey, who provided nursing and administrative support. The Health Services Research Unit receives core support from the Chief Scientist Office of the Scottish Executive Health Department. The views expressed are those of the authors.

Contributors: All authors contributed to the design of the study, adapted from a pilot study conceived by PDW, GPH, and AMG. CMAG, GPH, PDW, CMcA, HG, and GDL supervised the execution of the study and data collection. CMAG and GPH analysed the data. The paper was written jointly by all authors $\mathrm{CMAG}$ and $\mathrm{GPH}$ are guarantors for this paper.

Funding: WellBeing (grant sponsored by GlaxoWellcome) and Health Research Council of New Zealand.

Competing interests: None declared.

1 MacArthur C, Lewis M, Knox EG. Health after childbirth. London: HMSO, 1991.

2 Wilson PD, Herbison RM, Herbison GP. Obstetric practice and the prevalence of urinary incontinence three months after delivery. Br J Obste Gynaecol 1996;103:154-61.

3 MacArthur C, Lewis M, Bick D. Stress incontinence after childbirth. $\mathrm{Br}$ J Midwifery 1993;1:207-15.

4 MacArthur C, Bick DE, Keighley MRB. Faecal incontinence after childbirth. Br J Obstet Gynaecol 1997;104:46-50.

5 Sultan AH, Kamm MA, Hudson CN, Thomas JM, Bartram CI. Anal-sphincter disruption during vaginal delivery. $N$ Engl J Med 1993;329:1905-11.

6 Berghmans LC, Hendriks HJ, Bo K, Hay-Smith EJ, de Bie RA, van Waalwijk van Doorn ES, et al. Conservative treatment of stress urinary incontinence in women: a systematic review of randomized clinical trials. $\mathrm{BrJ}$ Urol 1998:82:181-91.

7 Hay-Smith EJ, Bo K, Berghmans LC, Hendriks HJ, De Bie RA, van Waalwijk van Doorn ES. Pelvic floor muscle training for urinary incontinence in women. Cochrane Database Syst Rev 2001;(1):CD001407.

8 Sleep J, Grant A. Pelvic floor exercises in postnatal care. Midwifery 1987;3:158-64

9 Snooks SJ, Badenoch DF, Tiptaft RC, Swash M. Perineal damage in genuine stress incontinence. An electrophysiological study. $\mathrm{Br} J$ Urol 1985;57:422-6.

10 Wilson PD, Herbison GP. A randomized controlled trial of pelvic floor muscle exercises to treat postnatal urinary incontinence. Int Urogynecol J Pelvic Floor Dysfunct 1998;9:257-64.

11 O'Brien J, Austin M, Sethi P, O'Boyle P. Urinary incontinence: prevalence, need for treatment, and effectiveness of intervention by nurse. $B M y$ 1991;303:1308-12.

12 Jozwik M, Jozwik M. The physiological basis of pelvic floor exercises in the treatment of stress urinary incontinence [review]. Br J Obstet Gynaecol 1998; 105:1046-51.

13 Millard RJ. Bladder control-a simple self-help guide. Sydney: MacLennan and Petty, 1987.

14 Mason L, Glenn S, Walton I, Hughes C. The instruction in pelvic floor exercises provided to women during pregnancy or following delivery. Midwifery 2001;17:55-64.

15 Zigmond AS, Snaith RP. The hospital anxiety and depression scale. Acte Psychiatr Scand 1983;67:361-70.

16 Norton C, Hosker G, Brazzelli M. Biofeedback and/or sphincter exercises for the treatment of faecal incontinence in adults. Cochrane Database Syst Rev 2000;(4):CD002111

17 Hosker G, Norton C, Brazzelli M. Electrical stimulation for faecal incontinence in adults. Cochrane Database Syst Rev 2000;(4):CD001310.

18 Cartwright A. Who responds to postal questionnaires? J Epidemiol Community Health 1986;3:267-73.

(Accepted 5 July 2001) 